\title{
Adult height in patients with childhood onset atopic dermatitis
}

\author{
Leena Patel, P E Clayton, Meriel E M Jenney, Janice E Ferguson, T J David
}

\begin{abstract}
Cross sectional studies have reported impaired growth in children with atopic dermatitis. If this growth impairment is irreversible, it would be expected to adversely influence final height attainment. The standing heights and other anthropometric parameters were assessed in 35 adults with onset of atopic dermatitis before 5 years of age and a control group of 35 adults with adult onset contact dermatitis or psoriasis.

There was no significant difference in the standing height SD score, midparental height SD score, sitting height SD score, subischial leg length SD score, nor body mass index between the atopic dermatitis and control groups. The standing height SD score was not significantly different among: (a) patients with atopic dermatitis affecting less than $50 \%$ of their body surface area and those with greater than $50 \%$ affected; (b) patients using the four different potency topical corticosteroids; and (c) patients with atopic dermatitis without asthma and those with coexisting asthma.

It is concluded that short stature is not a feature of our group of adult patients with onset of atopic dermatitis before 5 years of age, continuing into adulthood, and severe enough to require specialist care. This suggests that if growth impairment occurs in childhood, it is likely to be temporary and reversible.

(Arch Dis Child 1997;76:505-508)
\end{abstract}

Keywords: atopic dermatitis; growth, height; topical corticosteroids

Department of Child Health, University of Manchester

L Patel

P E Clayton

M E M Jenney

T J David

Department of

Dermatology,

University of

Manchester

J E Ferguson

Correspondence to :

Dr Leena Patel, Department of Child Health, Booth Hall Children's Hospital,

Charlestown Road, Blackley, Manchester M9 7AA.

Accepted 10 February 1997 and to compare these with the heights of adults without childhood onset skin disease. Our hypothesis was that adults with childhood onset atopic dermatitis would be shorter than adults without the disorder.

\section{Subjects and methods}

Thirty five adult patients (mean age 26.3 years, range $18-50$ years; 15 men, 20 women) with a history of onset of atopic dermatitis before 5 years of age continuing through childhood into adulthood, severe enough to require specialist care and attendance at a dermatology clinic, were studied between September 1992 and February 1994. No patient received systemic corticosteroids before 18 years of age.

Thirty five adult patients (mean age 31.6 years, range $18-46$ years; 15 men, 20 women) attending the dermatology clinic during the same period for adult onset contact dermatitis (27 patients) or adult onset psoriasis (eight patients) served as controls. Patients with a history of atopic dermatitis, asthma, allergic rhinitis, or food allergies were excluded as controls.

Patients with a known independent cause for short stature, history of long term systemic disease, or endocrine problems during childhood were excluded from the study and control groups.

The age at the onset of atopic dermatitis, the age when topical corticosteroid treatment was started, the potency of topical corticosteroid preparation used as described in the British National Formulary, the duration of treatment, the percentage body surface area affected, and the history of and treatment of asthma were recorded. Standing height (wall mounted Harpenden stadiometer), sitting height (Harpenden sitting height stadiometer), and weight (digital electronic scales) were measured. Reported parental heights were recorded for patients in the study and control groups. To standardise data for sex, SD scores were calculated for standing height, sitting height, subischial leg length, and parental heights using the standards of Tanner et al. ${ }^{5}$ Body mass index (BMI) was calculated from the ratio of weight to height ${ }^{2}$.

Variables for the two groups were compared using the two sample $t$ test. Ninety five per cent confidence intervals for differences were used to indicate the magnitude of the difference and to take the risks of type II errors into account. Correlation analysis was used to investigate the relations between anthropometric parameters and (a) the percentage body surface area affected by atopic dermatitis and (b) the age at which topical corticosteroid treatment was started. We estimated that 35 patients in each group would be required to detect a difference in mean standing height SD score of 0.5 with 
Table 1 Anthropometric data (mean (SEM)) of patients with atopic dermatitis and control subjects

\begin{tabular}{llll}
\hline & Atopic dermatitis & Control subjects & $\begin{array}{l}\text { p Value (95\% CI for } \\
\text { difference between means) }\end{array}$ \\
\hline $\begin{array}{llll}\text { Mid-parental height SD } \\
\quad \text { score }\end{array}$ & $-0.19(0.14)$ & $-0.15(0.15)$ & $0.8(-0.44$ to 0.36$)$ \\
$\begin{array}{l}\text { Standing height SD score } \\
\text { Sitting height SD score }\end{array}$ & $0.02(0.15)$ & $0.10(0.14)$ & $0.9(-0.37$ to 0.40$)$ \\
$\begin{array}{l}\text { Subischial leg length SD } \\
\quad \text { score }\end{array}$ & $-0.34(0.21)$ & $-0.13(0.19)$ & $0.5(-0.79$ to 0.36$)$ \\
BMI & $0.13(0.25)$ & $0.26(0.13)$ & $0.7(-0.72$ to 0.48$)$ \\
& $22.16(0.51)$ & $23.66(0.66)$ & $0.08(-3.17$ to 0.17$)$ \\
\hline
\end{tabular}

$80 \%$ power, assuming significance at the $5 \%$ level. A difference of less than 0.5 SD score would exclude any clinically important difference.

\section{Results}

ANTHROPOMETRY IN PATIENTS WITH ATOPIC DERMATITIS COMPARED WITH CONTROLS

There was no significant difference in standing height SD score, mid-parental height SD score (fig 1A), sitting height SD score, subischial leg length SD score, nor BMI between patients with atopic dermatitis and the control subjects (table 1). The heights of all patients with atopic dermatitis and all but one control subject (height SD score +2.92 ) fell within \pm 1.96 SDs of the means.

STANDING HEIGHT IN RELATION TO BODY SURFACE AREA AFFECTED BY ATOPIC DERMATITIS All patients with atopic dermatitis reported having extensive disease in childhood. At the

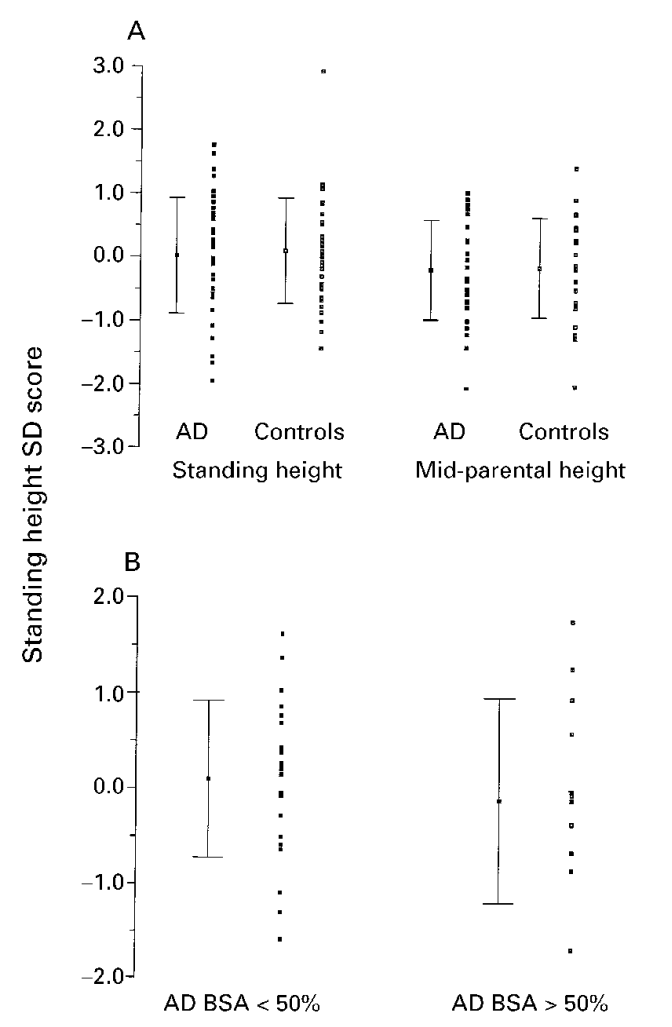

time of this study the patients had 9-90\% (median 33\%) of their body surface area affected by atopic dermatitis. The standing height SD score was not significantly different between patients with atopic dermatitis affecting less than $50 \%$ of their body surface area (mean height SD score 0.10, SEM 0.18) and those with greater than $50 \%$ affected (mean height SD score -0.11 , SEM 0.30, p = 0.5; $95 \%$ confidence interval (CI) -0.51 to 0.93 ) (fig 1B).

\section{EFFECT OF TOPICAL CORTICOSTEROID}

PREPARATIONS

Of the 35 patients with atopic dermatitis, seven, two, 16, and 10 patients, respectively, reported using mild potency (hydrocortisone $1 \%$ ), moderate potency (clobetasone butyrate $0.05 \%$, flurandrenolone $0.0125 \%$ ), potent (beclomethasone dipropionate $0.025 \%$, betamethasone valerate $0.1 \%$, fluocinolone acetonide $0.025 \%$, hydrocortisone butyrate $0.1 \%$ ), and very potent (clobetasol propionate $0.05 \%$ ) topical corticosteroids in childhood. Information about the amount of topical corticosteroid used during childhood was not available. The approximate age when regular topical corticosteroid treatment was started was reported by 23 patients: 11 patients before 1 year of age, eight patients between 1 and 4 years, and four patients between 7 and 12 years. The standing height SD score was not significantly different between the patients using different potency
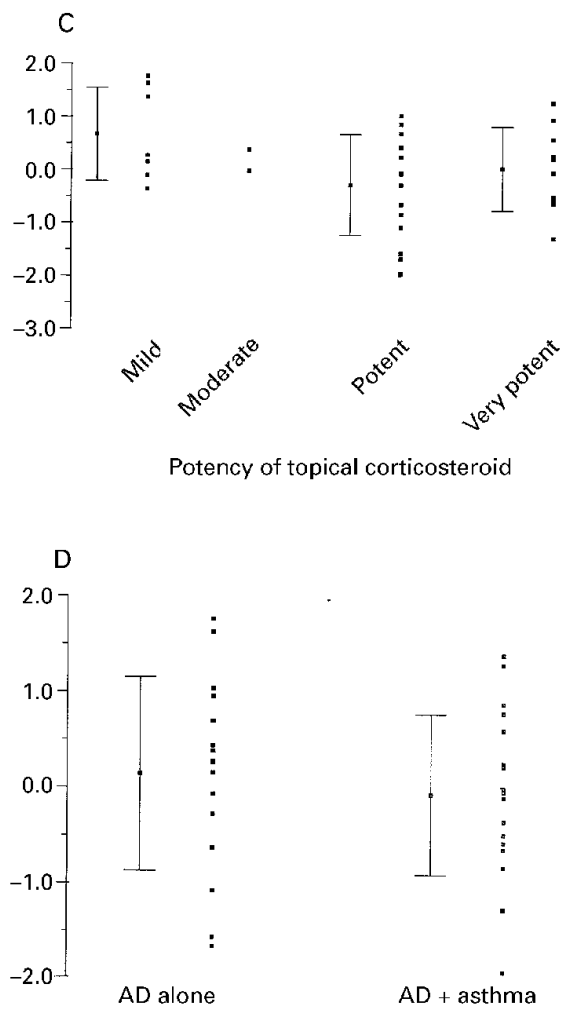

Figure 1 Standing height SD scores of: $(A) 35$ patients with atopic dermatitis $(A D)$ and 35 controls compared with mid-parental heights; (B) 22 patients with atopic dermatitis affecting less than $50 \%$ of their body surface area (AD BSA $<50 \%)$ and 13 patients with atopic dermatitis affecting greater than 50\% of their body surface areas (AD BSA >50\%); (C) seven, two, 16, and 10 patients with atopic dermatitis who had used mild potency, moderate potency, potent, and very potent topical corticosteroid preparations, respectively, from early childhood; and (D) 16 patients who had atopic dermatitis, but not asthma (AD alone), and 19 patients who had atopic dermatitis and asthma (AD + asthma). Means and SDs are shown by the horizontal bars. 
topical corticosteroids (fig 1C) and did not correlate significantly with the age at which topical corticosteroid treatment was started $(r=-0.14, \mathrm{p}=0.5)$.

Only one patient reported using topical corticosteroids under occlusion. This patient, aged 33 years, had started treatment with betamethasone valerate $0.1 \%$ at 3 years of age and remembered having occlusive treatment for a 'long time'. He had severe atopic dermatitis affecting $90 \%$ of his body surface area and from the age of 25 years he had been treated with corticosteroids by mouth, cyclosporin, and psoralens plus ultraviolet $\mathrm{A}$. He was the shortest of all the patients with atopic dermatitis and his standing height SD score and midparental height SD score were -1.95 and -0.68 , respectively.

STANDING HEIGHTS OF PATIENTS WITH ATOPIC DERMATITIS WITH AND WITHOUT COEXISTING ASTHMA

There was no significant difference in standing height SD score between the 16 patients with atopic dermatitis without asthma and the 19 patients with coexisting asthma $(\mathrm{p}=0.5 ; 95 \%$ $\mathrm{CI}-0.86$ to 0.43 ) (fig $1 \mathrm{D}$ ). Of the 19 patients with atopic dermatitis and asthma, four had received treatment with inhaled beclomethasone dipropionate in childhood. Their median standing height SD score was -0.21 .

\section{Discussion}

Our results do not support the hypothesis that adults with childhood onset atopic dermatitis are shorter than adults without the disorder. As the patients in the atopic dermatitis group had final heights that were not significantly different from the control group, they either (a) grew normally throughout childhood or (b) had temporary impaired growth during childhood. The latter is more likely as cross sectional studies in children with atopic dermatitis suggest that growth is impaired in childhood. ${ }^{1-3}$

From the observations of these previous studies of impaired growth in childhood, ${ }^{1-3}$ our own observation of normal adult height in patients with atopic dermatitis and the lack of a difference in the heights of patients with and without asthma, we speculate that children with atopic dermatitis have a similar pattern of growth to children with asthma, another atopic disorder. Children with asthma have been observed to have impaired growth in childhood, associated with delayed puberty, but to eventually attain normal final height..$^{6-8}$ Longitudinal assessment of growth of children with atopic dermatitis will show whether their pattern of growth is similar to that of children with asthma.

Growth suppression from long term systemic corticosteroid treatment is a well recognised cause of short stature during childhood in patients with chronic diseases such as atopic dermatitis and asthma. ${ }^{910}$ Percutaneous absorption of topical corticosteroids ${ }^{11}$ leading to growth impairment has been described previously. ${ }^{12-14}$ Considering that topical corticosteroids are widely used, the risk of growth impairment associated with them appears to be

\section{Key messages}

- Severe childhood atopic dermatitis does not impair final height attained

- Any growth impairment from atopic dermatitis in childhood is likely to be temporary

- Individual susceptibility to growth impairment from topical corticosteroid treatment may vary

- Children treated with topical corticosteroids need careful growth monitoring

low. Although our findings support this, our failure to find any differences in the heights of patients treated with different potency topical corticosteroids may be due to the small number of patients in each group. As growth impairment caused by corticosteroids is not necessarily irreversible, ${ }^{15}$ our study would not have identified any patient who had impaired growth that was followed by good catch up growth and hence the attainment of normal final height.

The patient who was treated with a potent topical corticosteroid with occlusion was inappropriately short and was the shortest patient in the study group. Although his short stature might be explained by his severe atopic disease, the effect of the topical corticosteroid treatment cannot be discounted. This patient and those reported previously ${ }^{12-14}$ are exceptional cases. There may well be individual variations in susceptibility to growth impairment from topical corticosteroids. This illustrates the need for continuing caution when using topical corticosteroid treatment and the need for careful growth monitoring.

We conclude that our group of adult patients with onset of atopic dermatitis before 5 years of age, continuing into adulthood, and severe enough to require specialist care were not short. This does not preclude the possibility that they might have had temporary growth impairment in childhood and a growth pattern of delayed puberty, as seen in patients with asthma.

We thank Dr M H Beck, Dr M Wilkinson, and Dr Simone Oliwiecki for letting us study their patients, and Sally Hollis for expert statistical advice.

1 Kristmundsdottir F, David TJ. Growth impairment in children with atopic eczema. $\mathcal{F} R$ Soc Med 1987;80:9-12.

2 Pike MG, Chang CL, Atherton DJ, Carpenter RG, Preece MA. Growth in atopic eczema: a controlled study by questionnaire. Arch Dis Child 1989;64:1566-9.

3 Massarano AA, Hollis S, Devlin J, David TJ. Growth in atopic eczema. Arch Dis Child 1993;68:677-9.

4 Voss LD, Mulligan J. Short normal stature-nature or nurture? (the Wessex growth study). Pediatr Res 1993; 33(suppl):321

5 Tanner JM, Whitehouse RH, Takaishi M. Standards from birth to maturity for height, weight, height velocity and weight velocity: British children 1965. Arch Dis Child 1966; 41:454-71, 613-35.

6 Hauspie R, Susanne C, Alexander F. Maturational delay and temporal growth retardation in asthmatic boys. $\mathcal{F}$ Allergy Clin Immunol 1977;59:200-6.

7 Balfour-Lynn L. Growth and childhood asthma. Arch Dis Child 1986;61:1049-55.

8 Martin AJ, Landau LI, Phelan PD. The effect on growth of Martin AJ, Landau LI, Phelan PD. The effect on growth
childhood asthma. Acta Paediatr Scand 1981;70:683-8.

9 Reichling GH, Kligman AM. Alternate-day corticosteroid therapy. Arch Dermatol 1961;83:980. 
10 Smith JM. Long term steroid treatment in asthmatic children. Ann Allergy 1965;23:492-6.

11 Turpeinen $M$. Influence of age and severity of atopic dermatitis on the percutaneous absorption of hydrocortisone in children. Brf Dermatol 1988;118:517-22.

12 Vermeer BJ, Heremans GFP. A case of growth retardation and Cushing's syndrome due to excessive application of betamethasone-17-valerate ointment. Dermatologica 1974, 149:299-304
13 Bode HH. Dwarfism following long-term topical corticosteroid therapy. FAMA 1980;244:813-4.

14 Turpeinen M, Salo OP, Leisti S. Effect of percutaneous absorption of hydrocortisone on adrenocortical responsiveness in infants with severe skin disease. Br f Dermatol 1986; 115:475-84.

15 Hyams JS, Carey DE. Corticosteroids and growth. F Pediatr 1988;113:249-54. 